\title{
Endoscopic drainage of a jejunopancreatic pseudocyst with an electrocautery- enhanced lumen-apposing metal stent
}

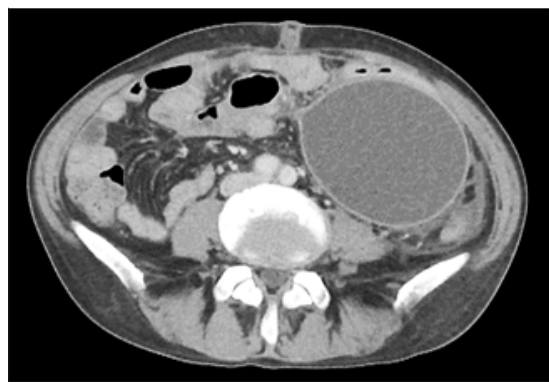

- Fig. 1 Computed tomography scan showing the pancreatic pseudocyst.

A 30-year-old man who was a known alcohol drinker $(216 \mathrm{~g} /$ day $)$ developed acute pancreatitis and a hemothorax after blunt trauma. He subsequently developed severe obstructive symptoms 12 weeks after the injury, which were caused by a 14-cm pancreatic pseudocyst (PPC) in the pancreatic tail, posterior to the transverse mesocolon ( $\bullet$ Fig. $\mathbf{1}$ ). The PPC abutted the proximal jejunum and was not apposed to the stomach, thereby precluding transgastric drainage.

Transluminal PPC drainage was therefore performed with a lumen-apposing metal stent (LAMS) and delivery system (Hot Axios; Boston Scientific, Natick, Massachusetts, USA) under fluoroscopic guidance using a convex-type ultrasound endoscope (GF-UCT260; Olympus, Tokyo, Japan) ( $\bullet$ Fig.2). The endoscope was inserted into the jejunum beyond the ligament of Treitz. The PPC was then directly punctured through the jejunal wall under ultrasound guidance with cauterization. The fully covered LAMS was inserted and expanded satisfactorily, resulting in massive fluid drainage without intraperitoneal spillage ( $\vee$ Fig. 3 ; $\vee$ Video 1$)$. The procedure took 2 minutes without device exchange. The patient's obstructive symptoms were relieved after drainage, with the pseudocyst significantly reduced in size ( $\bullet$ Fig. 4 ).
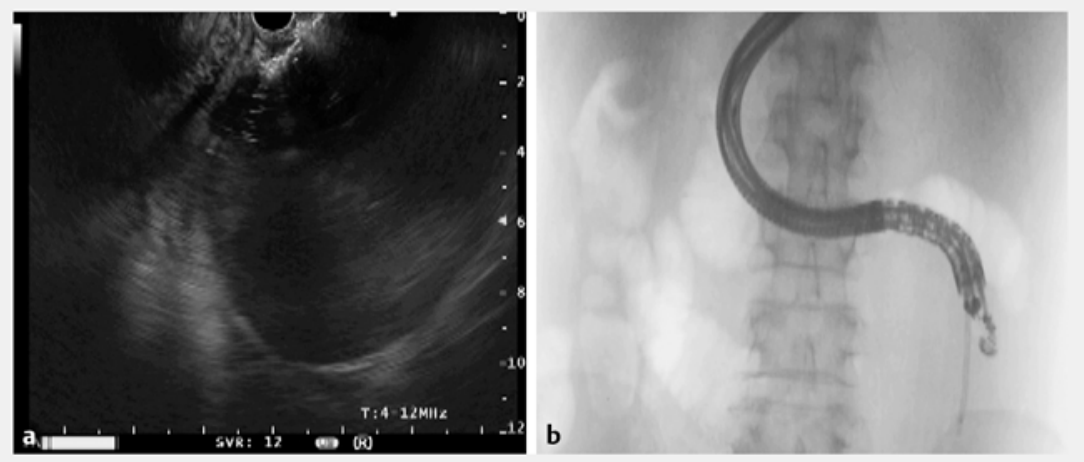

- Fig. 2 Ultrasound-guided puncture of the pancreatic pseudocyst using a single-step electrocautery-enhanced delivery system (Hot Axios) for a lumen-apposing metal stent shown: $\mathbf{a}$ on ultrasound image; $\mathbf{b}$ on fluoroscopic image.

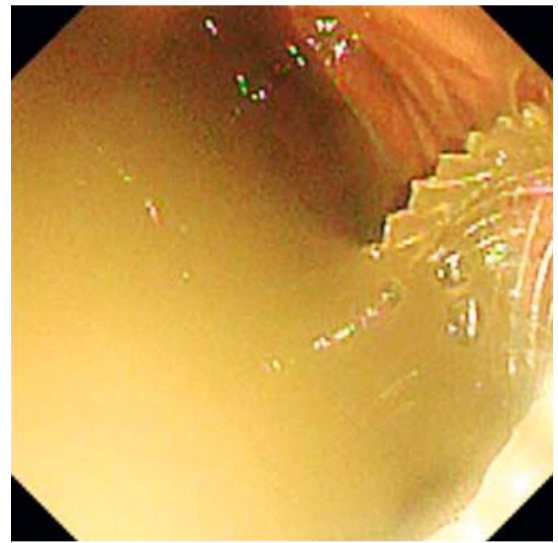

- Fig. 3 Massive fluid discharge from the pseudocyst into the jejunum through the lumen-apposing metal stent.

The Hot Axios is a novel single-step electrocautery-enhanced delivery system for a LAMS. The diathermic ring at the tip of device enables direct transmural access into a PPC or walled-off necrosis. The deployed fully-covered stent has two large flanges that minimize fluid leakage by compressing the walls of both the intestine and the PPC. Previous reports of PPC drainage have been performed through the stomach or duodenum [1-

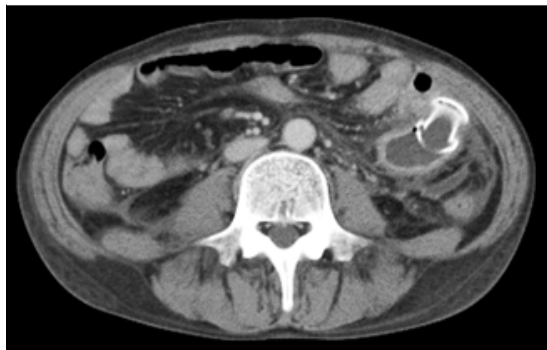

Fig. 4 Computed tomography scan showing that the pseudocyst was reduced in size after deployment of the lumenapposing metal stent.

3]. In this patient, the PPC was posterior to the transverse mesocolon, which precluded transgastric drainage. Successful drainage with a LAMS through the jejunum avoided laparotomy.

To our knowledge, this is the first report of transjejunal PPC drainage and it may be a viable option to treat patients with a PPC without going through the stomach. Further large studies are necessary to confirm the safety of transluminal jejunocystic drainage.

Endoscopy_UCTN_Code_TTT_1AR_2AI 


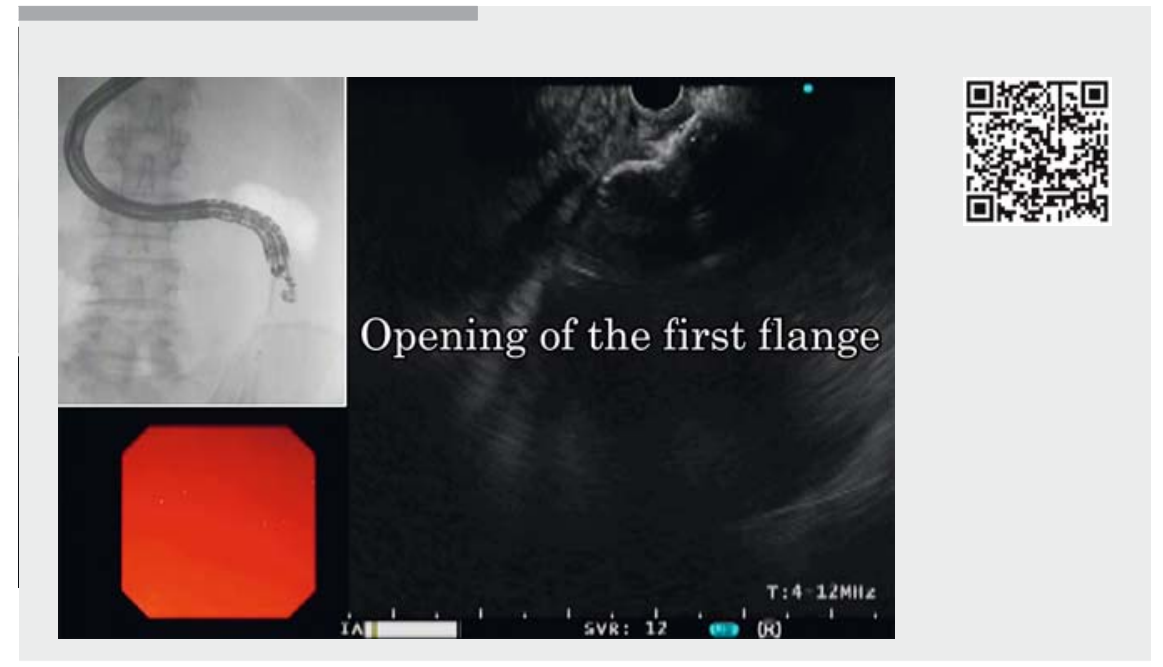

Video 1 Transluminal pancreatic pseudocyst drainage via the jejunum using single-step electrocautery-enhanced delivery of a lumen-apposing metal stent.

\section{Competing interests}

None

The authors

Toshiaki Terauchi ${ }^{1}$, Satoshi Shinozaki ${ }^{2,3}$, Kiyoto Mori ${ }^{4}$, Alan Kawarai Lefor ${ }^{5}$, Hiroharu Shinozaki ${ }^{1}$

1 Department of Surgery, Saiseikai Utsunomiya Hospital, Utsunomiya, Japan

2 Division of Gastroenterology, Department of Medicine, Jichi Medical University, Shimotsuke, Japan

3 Shinozaki Medical Clinic, Utsunomiya, Japan

4 Department of Gastroenterology, Saiseikai Utsunomiya Hospital, Utsunomiya, Japan

5 Department of Surgery, Jichi Medical University, Shimotsuke, Japan lumen-apposing covered self-expanding metal stents. Clin Gastroenterol Hepatol 2015; 13: 747 - 752

[3] Siddiqui AA, Adler DG, Nieto J et al. EUSguided drainage of peripancreatic fluid collections and necrosis by using a novel lumen-apposing stent: a large retrospective, multicenter U.S. experience (with videos). Gastrointest Endosc 2016; 83: 699-707

\section{Bibliography}

DOI https://doi.org/10.1055/a-0820-1585

Published online: 18.1.2019

Endoscopy 2019; 51: E67-E68

(c) Georg Thieme Verlag KG

Stuttgart · New York

ISSN 0013-726X

\section{ENDOSCOPY E-VIDEOS}

https://eref.thieme.de/e-videos

\section{Corresponding author}

\section{Satoshi Shinozaki, MD, PhD}

Shinozaki Medical Clinic, 6-1-13 Kiyoharadai, Utsunomiya, Tochigi, 321-3223, Japan shinozaki-s@aqua.ocn.ne.jp Fax: +81-28-6677305

\section{References}

[1] Yoo ], Yan L, Hasan R et al. Feasibility, safety, and outcomes of a single-step endoscopic ultrasonography-guided drainage of pancreatic fluid collections without fluoroscopy using a novel electrocautery-enhanced lumen-apposing, self-expanding metal stent. Endosc Ultrasound 2017; 6: 131-135

[2] Shah RJ, Shah JN, Waxman I et al. Safety and efficacy of endoscopic ultrasound-guided drainage of pancreatic fluid collections with 